\title{
CARACTERIZAÇÃO POR RESSONÂNCIA MAGNÉTICA NUCLEAR DE SUCOS DE MAÇÃ OBTIDOS POR PREPARAÇÕES ENZIMÁTICAS
}

Rosilene A. Prestes* e Denise Milléo Almeida

Coordenação de Alimentos, Universidade Tecnológica Federal do Paraná, Campus de Ponta Grossa, Av. Monteiro Lobato, s/n, km 4, 84016-210 Ponta Grossa - PR, Brasil

Andersson Barison

Departamento de Química, Universidade Federal do Paraná, Centro Politécnico, CP 19081, 81530-990 Curitiba - PR, Brasil

Luís Antonio Pinheiro

Departamento de Engenharia de Materiais, Universidade Estadual de Ponta Grossa, Av. Carlos Cavalcanti, 4748, 84030-900 Ponta

Grossa - PR, Brasil

Gilvan Wosiacki

Departamento de Engenharia de Alimentos, Universidade Estadual de Ponta Grossa, Av. Carlos Cavalcanti, 4748, 84030-900

Ponta Grossa - PR, Brasil

Recebido em 4/9/11; aceito em 19/1/12; publicado na web em 30/4/12

\begin{abstract}
NUCLEAR MAGNETIC RESONANCE CHARACTERIZATION OF APPLE JUICE CONTAINING ENZYME PREPARATIONS. In this work, ${ }^{1} \mathrm{H}$ Nuclear Magnetic Resonance $\left({ }^{1} \mathrm{H}\right.$ NMR) was employed to evaluate changes in apple juice in response to the addition of Panzym ${ }^{\circledR}$ Yieldmash and Ultrazym ${ }^{\circledast}$ AFP-L enzymatic complexes and compare it with premium apple juice. The juice was processed at different temperatures and concentrations of enzymatic complexes. The differences in the results were attributed mainly to the enzyme concentrations, since temperature did not cause any variation. A quantitative analysis indicated that the concentration of fructose increased while the concentrations of sucrose and glucose decreased in response to increasing concentrations of the enzymatic complexes.
\end{abstract}

Keywords: apple juice; enzyme preparations; NMR.

\section{INTRODUÇÃO}

O suco de maçã se destaca como o segundo mais consumido no mundo, logo atrás do suco de laranja. Processado pelo método tradicional, passa pelas etapas de seleção e lavagem da matéria-prima, trituração e prensagem, onde se origina o suco bruto. Para torná-lo pronto para o consumo, são ainda necessárias as etapas de despectinização, trasfega, filtração, engarrafamento e pasteurização, que deixam o suco clarificado. ${ }^{1}$ Este método produz um suco de boa qualidade, mas também produz um subproduto, o bagaço.

Como forma de se aumentar o rendimento do suco e reduzir a quantidade de bagaço, pode-se tratar a polpa da maçã com preparações enzimáticas. A modificação do perfil do bagaço se deve ao maior aproveitamento do mesmo pela tecnologia enzimática. ${ }^{2}$ Estes processos enzimáticos promovem a hidrólise da pectina e da celulose da polpa pelo efeito de uma ampla atividade enzimática, compreendendo poligalacturonase, pectinalises, pectinesterases, hemicelulases, arabanases e celulases. ${ }^{3,4} \mathrm{O}$ produto final desta complexa atividade na parede celular resulta em antocianinas, flavonóis e açúcares neutros como D-arabinose, D-galactose, L-ramnose e D-xilose. ${ }^{4-7}$ Os sucos obtidos dessa forma apresentam um aumento em compostos fenólicos, antocianinas e flavonóis. ${ }^{8-10}$

A produção de suco de maçã utilizando tecnologia enzimática está ligada ao emprego dos processos de maceração e liquefação. Ambos os processos degradam os polissacarídeos da parede celular, liberando compostos solúveis e neutros, e reduzem a viscosidade da polpa pela quebra das macromoléculas que compõem a parede celular da fruta. As preparações de maceração são compostas apenas por pectinases, enquanto as de liquefação possuem também celulases.

*e-mail: raprestes@yahoo.com.br
Por conta disso, esta última leva a uma quase total degradação dos polissacarídeos, enquanto aquela leva a um processo de degradação parcial. ${ }^{9}$ No entanto, ambas modificam profundamente a composição do bagaço, que não se presta mais como matéria-prima para a extração de fibras solúveis (pectinas) nem insolúveis, e deve ter um rendimento superior ao processo clássico do suco premium..$^{11}$

Sucos obtidos por preparações enzimáticas e as consequentes modificações químicas são avaliados por cromatografia de troca iônica e de exclusão por tamanho, cromatografia líquida para isolamento e determinação da concentração de coloides, ácido D-galacturônico, entre outros. ${ }^{12}$ Outros métodos de análise para sucos liquefeitos e macerados são refratômetro digital, phmetro, kit enzimático, espectroscopia de absorção atômica, análises gravimétricas, reagente de Folin-Ciocalteau, colorímetro, turbidímetro e titulação potenciométrica. ${ }^{13}$ Não obstante, a literatura relata poucos estudos de suco de maçã por ressonância magnética nuclear $(\mathrm{RMN}),{ }^{14,15}$ tampouco com preparações enzimáticas. O interesse na RMN surge por ser uma técnica que permite uma identificação deveras eficiente dos analitos presentes na amostra, sendo empregada, por exemplo, para a identificação de doenças em plantas, ${ }^{16}$ até atributos físicos-químicos de substâncias. ${ }^{17}$

Considerando o exposto, o objetivo deste trabalho foi investigar a influência do uso de preparações enzimáticas em sucos produzidos pelos processos de maceração e liquefação, analisando-se os metabólitos por RMN.

\section{PARTE EXPERIMENTAL}

\section{Materiais}

Maçãs da variedade Fuji e preparações enzimáticas de Ultrazym ${ }^{\circledR}$ 
AFP-L (Novozymes) (celulase + poligalacturonase) e Panzym ${ }^{\circledR}$ YieldMASH (Begerow) (poligalacturonase).

\section{Métodos}

Processamento do suco de maçã por centrifugação

As maçãs foram selecionadas, lavadas, pesadas e trituradas e, em seguida, $150 \mathrm{~g}$ de polpa foram colocadas em frascos de Erlenmeyer de 250 mL. As preparações enzimáticas Ultrazym ${ }^{\circledR}$ AFP-L e Panzym ${ }^{\circledR}$ YieldMASH foram adicionadas separadamente, em concentrações definidas pelo planejamento fatorial completo 3 x 4, na polpa. Para cada preparação enzimática as concentrações variaram de $0 ; 1,25$; 6,25 e $11,25 \mu \mathrm{L} / \mathrm{g}$. As concentrações de enzimas foram determinadas através de um teste preliminar em um viscosímetro do tipo Brookfield, onde foram testadas várias formulações, com peso constante de polpa e quantidade variável de preparação enzimática. Adotou-se a faixa de concentração e temperatura a partir da qual se observou diminuição na viscosidade da polpa.

Quanto às temperaturas, para Ultrazym ${ }^{\circledR}$ AFP-L foram de 20, 35 e $50{ }^{\circ} \mathrm{C}$, enquanto para a Panzym ${ }^{\circledR}$ YieldMASH, de 20,25 e $30^{\circ} \mathrm{C}$, conforme orientação técnica e observação pelo teste viscosimétrico. $\mathrm{O}$ sistema foi incubado sob agitação constante e temperatura controlada em shaker (Marconi) por $1 \mathrm{~h}$ e depois centrifugado em centrífuga de $800 \mathrm{~g}$ por $30 \mathrm{~min}$.

\section{Ressonância magnética nuclear (RMN)}

Os espectros de RMN de ${ }^{1} \mathrm{H}$ dos sucos de maçã foram obtidos em um espectrômetro de RMN Bruker Avance 400, operando a 9,4 Tesla, observando-se o núcleo de hidrogênio a 400,13 MHz, equipado com uma sonda multinuclear de detecção direta de $5 \mathrm{~mm}$. Os espectros foram adquiridos com sequência de pulsos de excitação de $90^{\circ}$ e sem supressão do sinal do solvente, 16 varreduras acumulativas. Nos espectros de ${ }^{1} \mathrm{H}$ a largura do pulso de $90^{\circ}$ foi de 7,5 $\mu$ s. O tempo de aquisição foi de 7,5 s e o tempo de reciclagem, $10 \mathrm{~s}$, totalizando $17,5 \mathrm{~s}$; equivalente a 5T1, conforme experimentos de inversão recuperação. O número de pontos de aquisição foi de $64 \mathrm{~K}$ e a janela espectral de 10 ppm, resultando em uma resolução digital de $0,06 \mathrm{~Hz}$. Para isso, $200 \mu \mathrm{L}$ de amostras de suco com e sem preparação enzimática foram dissolvidas em uma mistura prévia de $400 \mu \mathrm{L}$ de $\mathrm{D}_{2} \mathrm{O}$ e $60 \mu \mathrm{L}$ de dimetilsulfóxido (DMSO comum), contendo $0,03 \mathrm{mg}$ de 2,2,3,3- $\mathrm{D}_{4}$-trimetilsililpropionato de sódio tetradeuterado (TMSP- $d_{4}$ ) como referência interna, totalizando o volume de $660 \mu \mathrm{L}$. Os espectros de $\mathrm{RMN}$ de ${ }^{1} \mathrm{H}$ foram processados aplicando-se uma multiplicação exponencial dos FIDs por um fator de $0,3 \mathrm{~Hz}$ antes da transformada de Fourier, com auxílio do programa MestRe-C. Os deslocamentos químicos foram expressos em ppm, em relação ao sinal TMSP- $d_{4}$ em 0,00 ppm. ${ }^{16}$

\section{Quantificação dos açúcares por RMN}

Para a obtenção de cada espectro foram dissolvidas tanto as amostras quanto os padrões em $460 \mu \mathrm{L}$ da solução prévia e, em seguida, adicionados no tubo de RMN.

A quantificação dos açúcares presentes nos sucos estudados por RMN foi feita por normalização com relação à área do sinal em 2,7 ppm do padrão interno (DMSO), que foi adicionado sempre em concentração constante para todas as amostras. A concentração dos açúcares foi proporcional à razão entre a área do sinal analisado em relação ao sinal do DMSO. A integração foi realizada nas áreas dos sinais dos açúcares que pudessem ser claramente identificados e onde não havia qualquer sobreposição dos mesmos.

A análise quantitativa dos açúcares padrões e os presentes nas amostras de suco macerado e liquefeito, com e sem as preparações enzimáticas, foi realizada com auxílio do programa MestRe-C através da integração dos dois dupletos referentes a $\alpha(5,21 \mathrm{ppm})$ e $\beta(4,63$ ppm) glucose, onde foram integradas as regiões de 5,24 a 5,19 e 4,66 a 4,60 ppm, respectivamente. Na sacarose integrou-se o dupleto 5,39 ppm na região de 5,42 a 5,38 ppm e na frutose integrou-se o sinal relativo à região de 4,01 a 3,96 ppm (Tabela 1). Para a obtenção dos espectros dos açúcares padrões (sacarose, glucose e frutose)

Tabela 1. Valores da quantificação dos carboidratos (sacarose, frutose e $\alpha, \beta$-glucose) obtidos através da integração dos espectros de RMN

\begin{tabular}{|c|c|c|c|c|c|c|c|}
\hline & $\mathrm{T}\left({ }^{\circ} \mathrm{C}\right)$ & $\mathrm{C}(\mu \mathrm{L} / \mathrm{g})$ & Sacarose $\%$ & $\alpha$-Glucose $\%$ & $\beta$-Glucose $\%$ & $\alpha-\beta$ Glucose $\%$ & Frutose $\%$ \\
\hline \multirow{12}{*}{ Ultrazym $^{\circledR}$ AFPL } & \multirow{4}{*}{20} & 0,00 & 2,96 & 7,07 & 48,29 & 55,36 & 41,67 \\
\hline & & 1,25 & 3,88 & 8,7 & 45,18 & 53,88 & 42,22 \\
\hline & & 6,25 & 2,58 & 9,35 & 41,95 & 51,3 & 46,11 \\
\hline & & 11,25 & 0,16 & 5,97 & 50,32 & 56,29 & 43,53 \\
\hline & \multirow{4}{*}{35} & 0,00 & 4,4 & 9,53 & 43,34 & 52,87 & 42,71 \\
\hline & & 1,25 & 2,59 & 7,85 & 45,97 & 53,82 & 43,57 \\
\hline & & 6,25 & 4,36 & 10,81 & 43,34 & 54,15 & 41,46 \\
\hline & & 11,25 & 2,15 & 4,48 & 48,96 & 53,44 & 44,38 \\
\hline & \multirow{4}{*}{50} & 0,00 & 3,39 & 8,14 & 48,76 & 56,9 & 39,69 \\
\hline & & 1,25 & 3,1 & 7,95 & 45,83 & 53,78 & 43,1 \\
\hline & & 6,25 & 0,87 & 7,56 & 47,33 & 54,89 & 44,22 \\
\hline & & 11,25 & 3,94 & 11,04 & 41,5 & 52,54 & 43,49 \\
\hline \multirow{12}{*}{ Panzym ${ }^{\circledR}$ YieldMASH } & \multirow{4}{*}{20} & 0,00 & 5,19 & 10,83 & 43,66 & 54,49 & 40,30 \\
\hline & & 1,25 & 0,63 & 6,62 & 47,26 & 53,88 & 45,47 \\
\hline & & 6,25 & 3,04 & 9,64 & 42,44 & 52,08 & 44,87 \\
\hline & & 11,25 & 2,83 & 9,43 & 42,61 & 52,04 & 45,12 \\
\hline & \multirow{4}{*}{25} & 0,00 & 0,53 & 6,39 & 50,47 & 56,86 & 42,59 \\
\hline & & 1,25 & 3,45 & 9,05 & 44,53 & 53,58 & 42,95 \\
\hline & & 6,25 & 5,06 & 10,63 & 42,12 & 52,75 & 42,17 \\
\hline & & 11,25 & 3,36 & 9,61 & 42,24 & 51,85 & 44,77 \\
\hline & \multirow{4}{*}{30} & 0,00 & 4,1 & 10,08 & 43,02 & 53,1 & 42,78 \\
\hline & & 1,25 & 1,99 & 7 & 46,21 & 53,21 & 44,79 \\
\hline & & 6,25 & 1,26 & 6,59 & 45,41 & 52 & 46,72 \\
\hline & & 11,25 & 1,01 & 6,47 & 48,63 & 55,1 & 43,87 \\
\hline
\end{tabular}


utilizaram-se na construção de curvas cinco concentrações de cada $\left(3 \times 10^{-2} ; 275 \times 10^{-3} ; 25 \times 10^{-2} ; 20 \times 10^{-2}\right.$ e $\left.175 \times 10^{-3} \mathrm{mg}\right)$.

\section{RESULTADOS E DISCUSSÃO}

\section{Inspeção do efeito das preparações enzimáticas sobre a polpa por RMN}

Foram realizados estudos dos espectros de ${ }^{1} \mathrm{H}$ dos sucos com e sem preparações enzimáticas por espectroscopia de RMN para avaliação qualitativa e quantitativa. Os perfis dos sucos sem enzima (controle), macerado e liquefeito com concentração de enzima em $11,25 \mu \mathrm{L} / \mathrm{g}$ apresentaram diferenças mais significativas e serão apresentados.

A aplicação das duas preparações enzimáticas na polpa de maçã Fuji pode ser visualizada com eficiência quando os espectros são analisados em termos de quatro regiões: 4,20 a 4,08; 3,70 a 3,50; 3,04 a 2,00 e 1,60 a 0,80 ppm. Para estas regiões foram observadas variações mais significativas em termos quantitativos, principalmente na região dos carboidratos.

A Figura 1 apresenta os sucos controle e processado com a preparação enzimática Ultrazym ${ }^{\circledR} \mathrm{AFP}-\mathrm{L}$, na temperatura de $20^{\circ} \mathrm{C}$ para a região entre 4,20 e 4,08 ppm, sendo que nas demais temperaturas $\left(35\right.$ e $50{ }^{\circ} \mathrm{C}$ ) não se observaram variações significativas. $\mathrm{O}$ suco preparado pela Panzym ${ }^{\circledR}$ YieldMASH nas temperaturas de 20, 25 e $30{ }^{\circ} \mathrm{C}$ não será apresentado por ser semelhante ao suco liquefeito. A inspeção visual desta região apresenta um sinal desconhecido (1) para o suco liquefeito, não apresentado para os sucos controle e macerado. Outro sinal referente à frutose (2) foi encontrado em ambos os sucos. A observação da região do açúcar frutose (Figura 2), entre 3,70 e 3,50 ppm, mostra que não há alterações significativas em função da preparação enzimática, o mesmo ocorrendo com relação à temperatura e concentração.

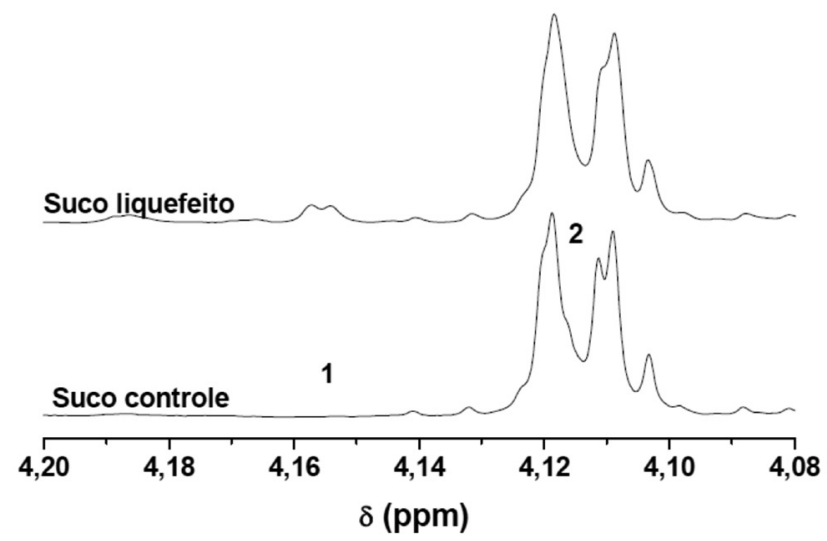

Figura 1. Expansão dos espectros de $R M N$ de ${ }^{1} H(400 \mathrm{MHz})$ na região de 4,20 a 4,08 ppm: comparação entre o suco liquefeito com a preparação enzimática Ultrazym ${ }^{\circledR}$ AFP-L e o suco controle, ambos tratados a $20^{\circ} \mathrm{C}$. A concentração das preparações enzimáticas foi de $11,25 \mu \mathrm{L} / \mathrm{g}$

As Figuras 3a e 3b das preparações enzimáticas Ultrazym ${ }^{\circledR}$ AFP-L e Panzym ${ }^{\circledR}$ YieldMASH, respectivamente, apresentam a expansão da região 3,04-2,00 ppm. Os valores de $\mathrm{pH}$ para o suco controle encontram-se dentro da faixa de 4,20 a 4,28 e para o suco liquefeito, no qual se utilizou a preparação enzimática Ultrazym ${ }^{\circledR}$ AFP-L, se encontraram valores entre 3,53 e 3,58. Para a preparação enzimática Panzym ${ }^{\circledR}$ Yieldmash os sucos controle e macerado apresentam valores de $\mathrm{pH}$ na faixa de 4,26 a 4,35 e 3,50 a 3,58, respectivamente. A redução dos valores do $\mathrm{pH}$ pode ter ocorrido devido à produção
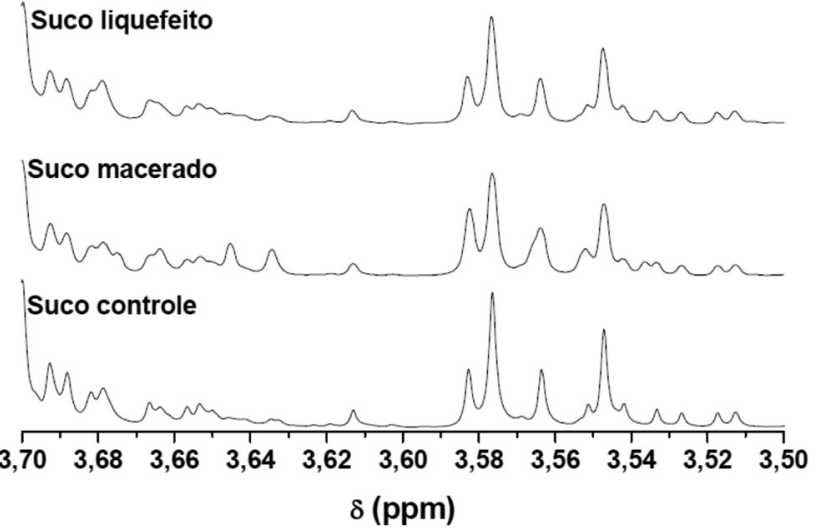

Figura 2. Expansão dos espectros de $\mathrm{RMN}$ de ${ }^{\mathrm{I}} \mathrm{H}(400 \mathrm{MHz})$ na região de 3,70 a 3,50 ppm: comparação entre o suco liquefeito com a preparação enzimática Ultrazym ${ }^{\circledR}$ AFP-L, suco macerado com a preparação enzimática Panzym ${ }^{\circledR}$ YieldMASH e o suco controle, tratados a $20^{\circ}$ C. A concentração das preparações enzimáticas foi de $11,25 \mu \mathrm{L} / \mathrm{g}$
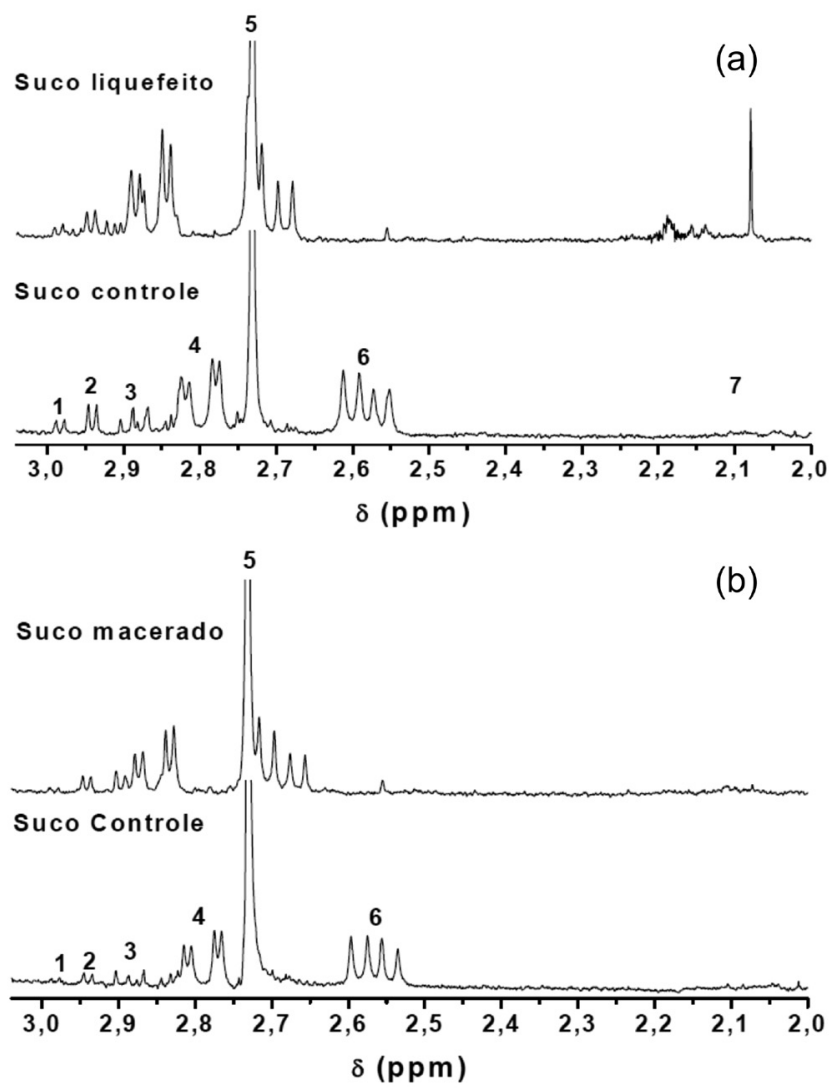

Figura 3. Expansão dos espectros de $\mathrm{RMN} \mathrm{de}{ }^{1} \mathrm{H}(400 \mathrm{MHz})$ na região de 3,04 a 2,00 ppm: a) comparação entre o suco liquefeito com a preparação enzimática Ultrazym ${ }^{\circledR}$ AFP-L e o suco controle, tratados a $20^{\circ} \mathrm{C}$; b) comparação entre o suco macerado com a preparação enzimática Panzym ${ }^{\circledR}$ YieldMASH e o suco controle, ambos tratados a $20^{\circ} \mathrm{C}$. Em ambos os casos, a concentração das preparações enzimáticas foi de $11,25 \mu \mathrm{L} / \mathrm{g}$

do ácido péctico durante o tratamento enzimático, pois as carboxilas das unidades galacturônicas podem estar livres. ${ }^{18}$

$\mathrm{O}$ efeito da alteração do $\mathrm{pH}$ pode ser claramente observado através da mudança nos sinais do ácido málico (4), o qual ocorre como um duplo dupleto ao redor de 4,36 ppm e dois duplos dupletos centrados ao redor de 2,80 ppm para o suco controle. Nos sucos com preparação enzimática, devido à variação do $\mathrm{pH}$, pode-se observar 
deslocamento químico do ácido málico para maiores valores de deslocamento químico.

A variação de $\mathrm{pH}$ também interferiu no deslocamento químico do ácido succínico. Nestes sucos observou-se aumento da acidez quando a preparação enzimática foi acrescentada de 0,19 para $0,41 \mathrm{~g} / 100 \mathrm{~mL}$ para Ultrazym $^{\circledR}$ AFP-L e de 0,13 a 0,28 g/100 mL) para Panzym ${ }^{\circledR}$ YieldMASH. Moléculas cujo estado de ionização não mudam na faixa de $\mathrm{pH}$ de interesse não mostram nenhum deslocamento químico devido ao efeito do $\mathrm{pH}$. Isto se aplica à maior parte dos açúcares onde os deslocamentos químicos permanecem constantes em todas as amostras analisadas, mas não às intensidades relativas. ${ }^{15}$ São vistos nestes espectros sinais na região de 3,0 ppm da asparagina (1) e sinais, referentes aos números 2 e 3 , de aminoácidos, não identificados. A região de 2,7 ppm referente ao padrão interno DMSO comum (5) e em 2,6 ppm do ácido succínico (6). Os ácidos clorogênico e quínico deveriam ser encontrados na região de 2,2 a 2,0 ppm, porém observou-se somente a presença do ácido acético (7) nos sucos com preparação enzimática Ultrazym ${ }^{\circledR}$ AFP-L. Os ácidos clorogênico e quínico surgem principalmente a partir de ácido quínico, que, no suco de maçã, ocorre tanto em relação à forma livre, como parte de ácido clorogênico. ${ }^{19}$

A inspeção visual da região 1,06-0,80 ppm (Figura 4) mostra variação entre os sucos controle, macerado e liquefeito. No suco controle, processado na temperatura de $20{ }^{\circ} \mathrm{C}$, os principais sinais encontrados são de alcoóis, como o propanol (1) e etanol (6). Também foram identificados satélites do etanol nas regiões de 1,36 e 1,30 e na região de 1,05 a 1,00 , referentes aos sinais (3) e (7) do espectro. Para este suco ainda foi encontrado o sinal da alanina (2) e desconhecido (4). Nos sucos estudados em outras temperaturas observa-se que alguns sinais não estão aparecendo à medida que a temperatura aumenta, como os sinais do etanol e seus satélites.
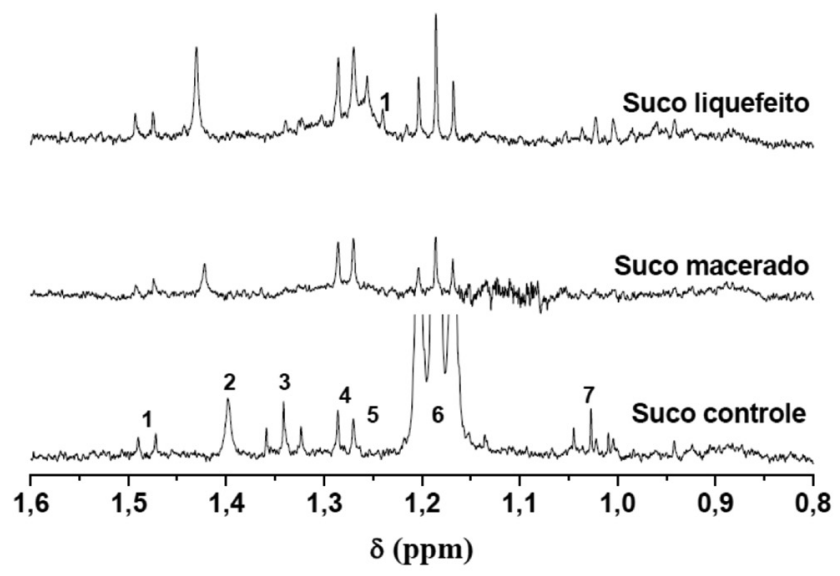

Figura 4. Expansão dos espectros de $\mathrm{RMN}$ de ${ }^{l} \mathrm{H}(400 \mathrm{MHz})$ na região de 1,60 a 0,80 ppm: comparação entre o suco liquefeito com a preparação enzimática Ultrazym ${ }^{\circledR}$ AFP-L, suco macerado com a preparação enzimática Panzym ${ }^{\circledR}$ YieldMASH e o suco controle, tratados a $20^{\circ}$ C. A concentração das preparações enzimáticas foi de $11,25 \mu \mathrm{L} / \mathrm{g}$

Os sucos processados com preparação enzimática Panzym ${ }^{\circledR}$ YieldMASH e Ultrazym ${ }^{\circledR}$ AFP-L apresentaram em seus espectros os mesmos sinais quando comparados com o suco controle, apenas a intensidade dos sinais satélites do etanol (3) e (7) diminuiu para ambos os sucos. O suco com preparação Ultrazym ${ }^{\circledR}$ AFP-L apresentou para todas as temperaturas estudadas um sinal desconhecido (5) na região de 1,26 a 1,23. O etanol e o propanol encontrados na maioria dos espectros podem ser consequência de ação microbiológica. ${ }^{15}$

\section{Quantificação dos açúcares}

A Figura 5 mostra uma curva de calibração para a determinação do teor do açúcar frutose. Nela se observa a razão entre a integração dos sinais de frutose e DMSO em função da concentração do açúcar. O coeficiente de correlação para frutose foi de 0,98 ; enquanto para sacarose e glucose foi de 0,98 e 0,96 , respectivamente.

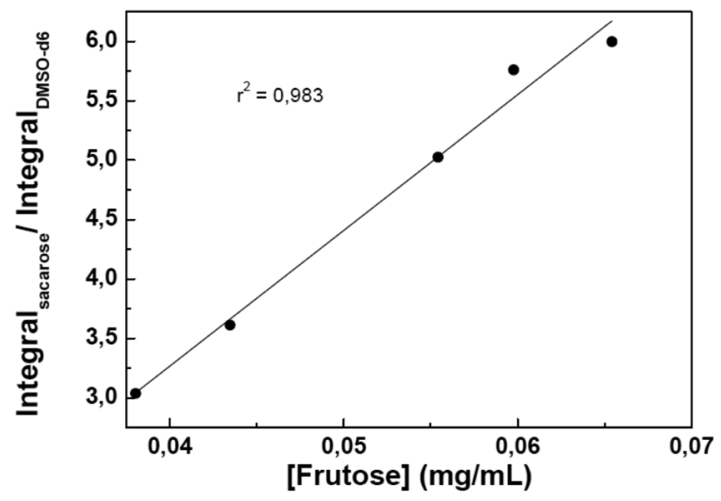

Figura 5. Curva de calibração para o teor de frutose

A partir das curvas das amostras se determinou, por integração, a área referente ao sinal de cada açúcar e dividiu-se pelo de DMSO. A concentração dos açúcares foi somada e a Tabela 1 apresenta os valores percentuais de cada açúcar nas amostras. Nesta tabela observa-se que a sacarose e a $\alpha$-glucose apresentaram tendência à diminuição, de acordo com o aumento da concentração enzimática para as duas preparações. No entanto, a frutose aumentou com a variação dos parâmetros tempo e concentração para ambas as enzimas.

Na preparação enzimática Ultrazym ${ }^{\circledR}$ AFP-L o perfil quantitativo da $\beta$-glucose apresentou uma tendência a aumento, à medida que a concentração enzimática variou para as temperaturas de 20 e $35^{\circ} \mathrm{C}$ e diminuição para a temperatura de $50^{\circ} \mathrm{C}$, enquanto na preparação Panzym ${ }^{\circledast}$ YieldMASH ocorreu o contrário.

\section{CONCLUSÃO}

A inspeção por RMN mostrou que o uso de preparações enzimáticas no processamento de suco de maçã dá origem a produtos muito similares àqueles sem enzimas. Nas faixas entre 4,2 e 4,08 e 3,7 e 3,5 ppm apresentam diferenças somente em função do processamento e da presença de enzimas, não sendo sensíveis à temperatura e concentração da preparação enzimática. Observou-se um deslocamento de sinais referentes aos ácidos málico e succínico na faixa entre 3,04 e 2,0 ppm, para valores maiores de deslocamento químico em decorrência da variação de $\mathrm{pH}$ dos sucos. A análise quantitativa, realizada por meio de dados de calibração, mostrou que a sacarose e a $\alpha$-glucose apresentaram tendência à diminuição, de acordo com o aumento da concentração enzimática para as duas preparações, enquanto a frutose aumentou com a variação dos parâmetros tempo e concentração para ambas as enzimas. Os resultados também apresentaram diferenças quantitativas no conteúdo de carboidratos, $\mathrm{pH}$ e acidez.

\section{REFERÊNCIAS}

1. Vicenzi, R.; Bilhalva, A. B.; Treptow, R. O.; Ciênc. Tecnol. Aliment. 2001, 21, 257.

2. Landbo, A. K.; Meyer, A. S.; Innovative Food Sci. Emerg. Technol. 2004, 5, 503; Sinitsyna, O. A.; Fedorova, E. A; Semenova, M. V.; Gusakov, A. V.; Sokolova, L. M.; Bubnova, T. M.; Okunev, O. N.; Chulkin, A. M.; Vavilova, E. A.; Vinetsky, Y. P.; Sinitsyn, A. P.; Biochemistry 2007, 72, 
565; Demir, N.; Acar, J.; Sarioglu, K.; Muttlu, M.; J. Food Eng. 2001, 47, 275.

3. Acar, J.; Fruit Process. 1999, 8, 314.

4. Pap, N.; Pongrácz, E.; Jaakkola, M.; Tolonen, T.; Virtanen, V.; Turkki, A.; Horváth-Hovorka, Z.; Vatai, G.; Keiski, R. L.; J. Food Eng. 2010, $98,429$.

5. Grassin, C.; Fauquembergue, P.; Fruit Process. 1996, 5, 490.

6. Will, F.; Mehrlander, K.; Dietrich, H.; Dongowski, G.; Sebries, S.; Fruit Process. 2003, 12, 429.

7. Markowski, J.; Mieszczakowska, M.; Płocharski, W.; Int. J. Food Sci. Technol. 2009, 44, 1002.

8. Oszmianski, J.; Wojdylo, A.; Kolniak, J.; J. Agric. Food Chem. 2009, 57, 7078 .

9. Centenaro, G. S.; Prentice-Hernández, C.; Salas-Mellado, M.; Maria Netto, F.; Quim. Nova 2009, 32, 1792.

10. Oliveira, M. C. S.; Dissertação de Mestrado, Universidade Estadual de Ponta Grossa, Brasil, 2006.

11. Uenojo, M.; Pastore, G. M.; Quim. Nova 2007, 30, 388.

12. Mehrlander, K.; Dietrich, H.; Sembries, S.; Dongowski, G.; Will, F.; J. Agric. Food Chem. 2002, 50, 1230.
13. Jaroslaw, M.; Fastyn, M.; Plocharski, W.; Urlaub, R.; Dadas, A.; Fruit Process. 2009, 18, 118; Will, F.; Bauchhage, K.; Dietrich, H.; Eur. Food Res. Technol. 2000, 211, 291; Oszmianski, J.; Wojdylo, A.; Fruit Process. 2006, 15, 322.

14. Campo, G.; Santos, J. I.; Iturriza, N.; Berregi, A.; Munduate, A.; J. Agric. Food Chem. 2006, 54, 3095.

15. Belton, P. S.; Delgadillo, I.; Gil, A. M.; Roma, P.; Casuscelli, F.; Colquhoun, I. J.; Dennis, M. J.; Spraul, M.; Magn. Reson. Chem. 1997, 35, S52.

16. Prestes, R. A.; Colnago, L. A.; Forato, L. A.; Carrilho, E.; Bassanezi, R. B.; Wulff, N. A.; Mol. Plant Pathol. 2009, 10, 51.

17. Prestes, R. P.; Colnago, L. A.; Forato, L. A.; Vizzotto, L.; Novotny, E. H.; Carrilho, E.; Anal. Chim. Acta 2007, 596, 325.

18. Khallouk, M.; Rutledge, D. N.; Silva, A. M. S.; Delgadillo, I.; Magn. Reson. Chem. 2005, 43, 309.

19. Girolamo, A.; Solfrizzo, M.; Vitti, C.; Visconti, A.; J. Agric. Food Chem. 2004, 52, 6478; De Maria, C. A. B.; Moreira, R. F. A.; Quim. Nova 2004, 27, 586; Boffo, E. F.; Ferreira, A. G.; Quim. Nova 2006, 29, 456. 